\title{
Investigation of Hot Formability of AZ61 Mg Alloy
}

\author{
Maziar Ramezani, Thomas Neitzert \\ Department of Mechanical Engineering, Auckland University of Technology, Auckland, New Zealand \\ Email: maziar.ramezani@aut.ac.nz, thomas.neitzert@aut.ac.nz
}

Received 26 February 2015; accepted 21 April 2015; published 24 April 2015

Copyright (C) 2015 by authors and Scientific Research Publishing Inc.

This work is licensed under the Creative Commons Attribution International License (CC BY). http://creativecommons.org/licenses/by/4.0/

(c) (i) Open Access

\begin{abstract}
High temperature mechanical properties and formability of the AZ61 magnesium alloy are evaluated in this paper. Tensile tests were conducted to obtain the formability parameters at elevated temperatures of up to $400^{\circ} \mathrm{C}$. The results showed that at higher temperature, yield strength and ultimate tensile strength of the material decrease significantly, while the material experiences an increase in ductility (maximum elongation before break). A model has been created in finite element software Abaqus to further study the deep drawability of the AZ61 Mg alloy. Effects of different process parameters such as punch and die geometry, forming speed and temperature as well as blank-holder force on square cup drawing of the AZ61 alloy were investigated and optimum process parameters are obtained which can be used as a design guide in sheet metal forming industry.
\end{abstract}

\section{Keywords}

AZ61, Deep Drawing, FE simulation, Formability, Magnesium

\section{Introduction}

Magnesium alloys offer high specific strength and stiffness with good shock absorption, weldability and castability. Moreover, magnesium alloys are light structured so they have a great potential in the automotive and aerospace industries for body weight reduction which would decrease fuel consumption and the emission of carbon dioxide gas which would be of great importance for the environment [1]. However, the use of magnesium alloys has been restricted due to its comparably low formability at room temperature. This is due to the fact that they have a hexagonal close packed (HCP) crystal structure and show a low tendency to twinning [2]. Therefore, it is better to form magnesium alloys at elevated temperatures in order to activate additional slip planes and thereby improving material ductility and formability [3]. 
AZ61 is a commercially available magnesium alloy with $6 \%$ aluminium, as indicated by the first numerical digit in the designation; the second digit represents a zinc content of $1 \%$. Several other trace elements can also be found such as copper, silicon, iron and nickel as listed in Table 1; however, these elements have little effect on the microstructure of the alloy [4].

Several papers have been published recently investigating hot deformation and mechanical properties of AZ61 alloy (see e.g. [5]-[11]); however, no computer simulation of deep drawability of this alloy is available in literature. In this project the aim was to assess the hot workability of the fine grain AZ61 Mg alloy. This was undertaken by the use of experimental and FE simulation analyses. Tensile tests have been conducted at temperatures up to $400^{\circ} \mathrm{C}$ and mechanical properties have been measured at each temperature. These data are used to develop a finite element model to further investigate the formability of this alloy under deep drawing condition. We carried out deep drawing simulations of AZ61 thin sheets and demonstrated their high drawing ratio at hot stamping process. Maximum drawing depth before fracture was considered as the characteristic quantity of formability. The effect of different process parameters on the deep drawability of the AZ61 alloy has been studied with the developed FE model.

\section{Tensile Tests}

The experimental material was the hot rolled AZ61 Mg alloy sheet. Its chemical composition is listed in Table 1. The as-received specimen had an average grain size of $8.6 \mu \mathrm{m}$. Tensile tests were performed in rolling direction at forming speed of $3 \mathrm{~mm} / \mathrm{min}$ at temperatures ranging from $100^{\circ} \mathrm{C}$ to $400^{\circ} \mathrm{C}$. The AZ61 alloy studied here, was received as rolled in the form of a sheet with $0.8 \mathrm{~mm}$ thickness. Tensile specimens were cut from the sheet according to ASTM E646-07 standard. A muffle furnace was used that would cover and surround the tensile specimen and transfer the heat generated to the specimen. The experimental set-up is shown in Figure 1.

During the experiment, temperature control was performed with a thermocouple joined to the surface of the specimen. The tensile specimen was fixed by two pins in the grippers of the tensile tester. The thermocouple readings show the actual temperature of the specimen. A digital controller measures the temperature in the upper, middle and lower sections of the furnace during the test. Each test has been repeated three times and the average values are reported here.

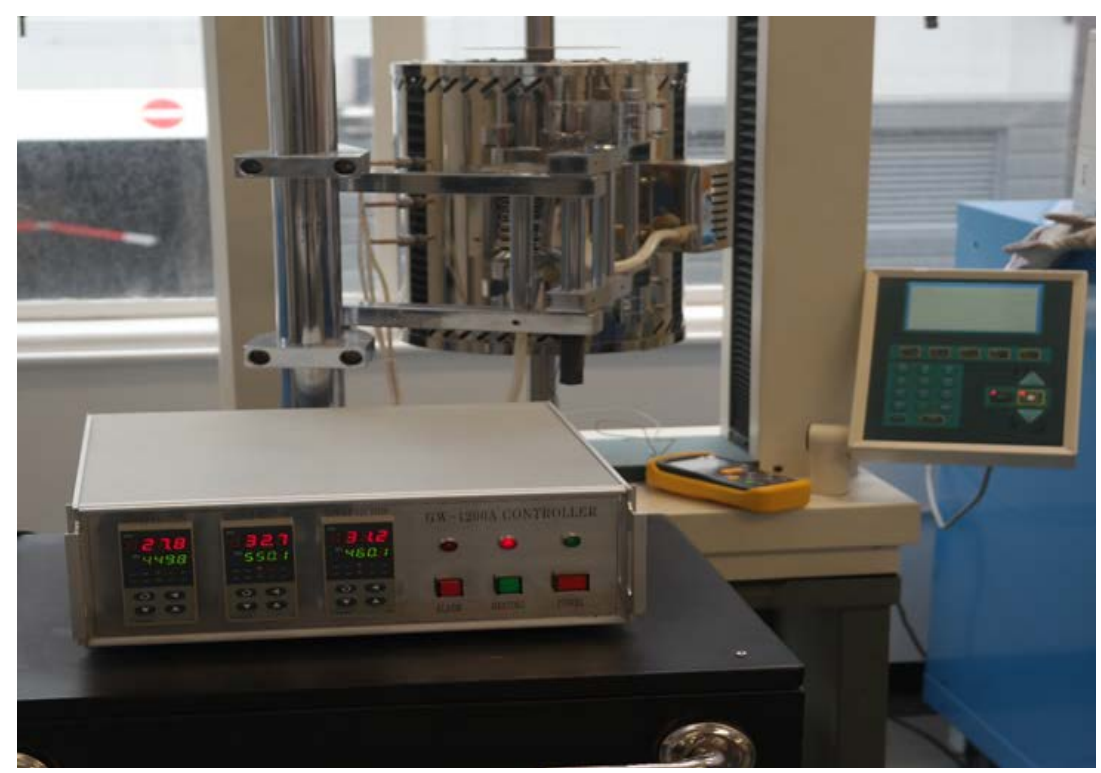

Figure 1. High temperature tensile testing set-up.

Table 1. Chemical composition of AZ61 magnesium alloys.

\begin{tabular}{cccccccc}
\hline Element & $\mathrm{Al}$ & $\mathrm{Zn}$ & $\mathrm{Cu}$ & $\mathrm{Si}$ & $\mathrm{Fe}$ & $\mathrm{Ni}$ & $\mathrm{Mg}$ \\
\hline \% by mass & $5-7$ & $0.8-1$ & $<0.03$ & $<0.01$ & $<0.01$ & $<0.005$ & Balance \\
\hline
\end{tabular}




\section{Deep Drawing Simulations}

Finite element simulation of square cup drawing is performed in ABAQUS software to investigate the effects of different process parameters such as punch radius, die corner radius, punch speed, blank holder force and temperature on the maximum depth of the cup. Table 2 shows the default process parameters used to simulate the process.

A square blank with the dimensions of $150 \mathrm{~mm}$ by $150 \mathrm{~mm}$ and a thickness of $0.8 \mathrm{~mm}$ was used for the deep drawing simulations. The rigid die has a flat surface with a square hole of $102 \mathrm{~mm}$ by $102 \mathrm{~mm}$ with a die corner radius of $5 \mathrm{~mm}$. The rigid square punch has dimensions of $100 \mathrm{~mm}$ by $100 \mathrm{~mm}$ with a punch radius of $10 \mathrm{~mm}$. The rigid blank holder is considered as a flat plate since the blank never comes close to its edges.

Due to the symmetry of the square cup, only a quarter was modelled to make it easier to visualise stress distribution and to reduce computing time. All parts were modelled as rigid bodies except for the blank which is modelled as an elastic/plastic material. The material properties of the AZ61 magnesium alloy were obtained from high temperature tension tests. A density of $1800 \mathrm{~kg} / \mathrm{m}^{3}$ is implemented in the model. The simulation begins with the blank in contact with the die and the blank holder. The punch then moves down to stamp the blank. The interface between the die and the blank, the blank-holder and the blank, and the blank and the punch are modelled using an automatic surface to surface contact algorithm. Figure 2 shows the FE model at the end of the process. Earing has taken place in the flange region of the sheet metal blank which is due to the square geometry of the blank.

\section{Results and Discussions}

Table 3 shows the mechanical properties of the AZ61 alloy at different temperatures ranging from $100^{\circ} \mathrm{C}$ to $400^{\circ} \mathrm{C}$ obtained from tensile tests. It can be seen from the results that yield strength and ultimate tensile stress decrease at higher temperatures, while maximum elongation before fracture increases significantly at higher temperatures and plateaus.

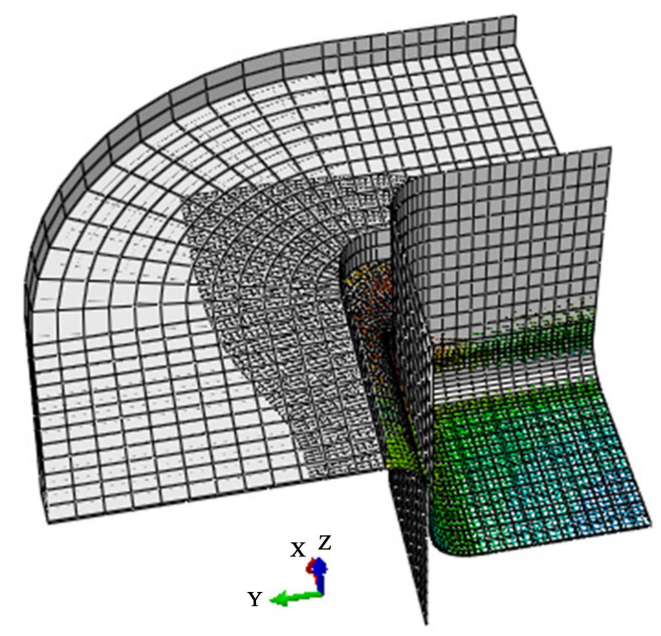

Figure 2. High temperature tensile testing set-up.

Table 2. Process parameters for FEA simulations.

\begin{tabular}{cc}
\hline Punch speed & $60 \mathrm{~mm} / \mathrm{min}$ \\
\hline Blank holder force & $3 \mathrm{kN}$ \\
Friction coefficient & 0.1 \\
Punch radius & $10 \mathrm{~mm}$ \\
Die corner radius & $5 \mathrm{~mm}$ \\
Temperature & $250^{\circ} \mathrm{C}$ \\
\hline
\end{tabular}


Table 3. Mechanical properties of AZ61 magnesium alloy at elevated temperatures.

\begin{tabular}{ccccc}
\hline Temperature $\left({ }^{\circ} \mathrm{C}\right)$ & Young's modulus (GPa) & Yield stress (MPa) & Ultimate tensile stress (MPa) & Elongation before break (\%) \\
\hline 20 & 46 & 204 & 313 & 9 \\
100 & 29 & 196 & 276 & 26 \\
150 & 26 & 175 & 220 & 59 \\
200 & 160 & 193 & 86 & 90 \\
240 & 19 & 94 & 121 & 84 \\
300 & 16 & 94 & 72 & 88 \\
\hline
\end{tabular}

Figure 3 shows the contour plot for the plastic strain in the drawn cup at temperature of $250^{\circ} \mathrm{C}$ and process parameters listed in Table 2. It is seen that the maximum plastic strain takes place at the corner of the cup due to biaxial stretch. The contour plot shown in Figure 4 shows the distribution of the maximum principal stress. Maximum thinning is observed at the cup wall. The flange region shows a high wrinkling tendency.

The punch radius was varied from $7 \mathrm{~mm}$ to $19 \mathrm{~mm}$ to investigate its effect on maximum depth of the cup before fracture occurs. It can be seen from Figure 5 that a maximum draw depth of $35.6 \mathrm{~mm}$ could be achieved for a punch radius of $19 \mathrm{~mm}$. It is known that a smaller punch radius restrains the material from flowing equally in all directions, resulting in a major increase in strain causing an early fracture. A large punch radius on the other hand allows for an equal biaxial stress at the corners of the cup which delays fracturing.

The die corner radius was varied from $3 \mathrm{~mm}$ to $7 \mathrm{~mm}$ while fixing other parameters listed in Table 2. According to Figure 6, an optimum die corner radius of $6 \mathrm{~mm}$ was found corresponding to a maximum draw depth of $33.7 \mathrm{~mm}$. When the die corner radius is smaller than $5 \mathrm{~mm}$, the draw depth turns toward a smaller value. Figure 7 shows the variation of maximum cup depth versus punch speed. A maximum draw depth of $33.9 \mathrm{~mm}$ was achieved at an optimum punch speed of $100 \mathrm{~mm} / \mathrm{min}$. Overall, the results show that the effect of ram speed on maximum drawing depth is not remarkable.

The graph for the blank-holder force against draw depth is shown in Figure 8. The optimum blank-holder force is $3 \mathrm{kN}$ leading to a maximum draw depth of $33.6 \mathrm{~mm}$. When the blank-holder force is too high or too low, fracture or wrinkling may occur, respectively. A blank-holder force of $6 \mathrm{kN}$ has the lowest draw depth of 26.4 $\mathrm{mm}$.

Temperature was varied from $50^{\circ} \mathrm{C}$ to $400^{\circ} \mathrm{C}$ while fixing the tool geometry, punch speed and blank-holder force. It is clear from Figure 9 that the AZ61 magnesium alloy sheet shows excellent formability at elevated temperatures. An optimum forming temperature of $250^{\circ} \mathrm{C}$ corresponds to a maximum cup depth of $33.6 \mathrm{~mm}$. The AZ61 magnesium sheet is more susceptible to fracture at temperature below $150^{\circ} \mathrm{C}$. The graph for coefficient of friction against draw depth is shown in Figure 10. The draw depth varies from $28 \mathrm{~mm}$ to $33.6 \mathrm{~mm}$ through the range of friction coefficients used in the FE simulations. The maximum cup depth was achieved at an optimum friction coefficient of 0.1 .

\section{Conclusion}

This study aimed at expanding the application of AZ61 Mg alloy sheets as a structural material. This alloy has rarely been used as sheet materials in press forming and examined its deep drawability. Mechanical properties and formability of AZ61 magnesium alloy were studied using tensile tests at elevated temperatures. Square cup formability of AZ61 magnesium alloy sheet was also investigated by computer simulations. The maximum draw depth of the square cup without fracture was used as an index of formability. The results showed that formability of AZ61 alloy improves significantly at elevated temperatures. An optimum deep drawing temperature of $250^{\circ} \mathrm{C}$ was achieved with a maximum draw depth of $33.6 \mathrm{~mm}$. The effect of key process parameters on deep drawability of the AZ61 alloy was investigated by FE simulations and the optimum parameters were found for punch 


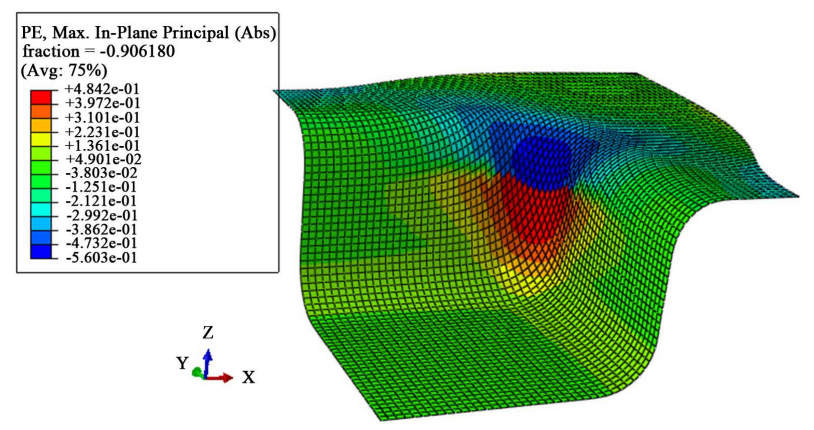

Figure 3. Distribution of plastic strain in the drawn cup.

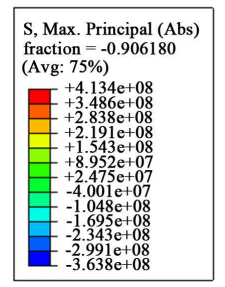

$$
\stackrel{\mathrm{Z}}{\mathrm{L}} \mathrm{x}
$$

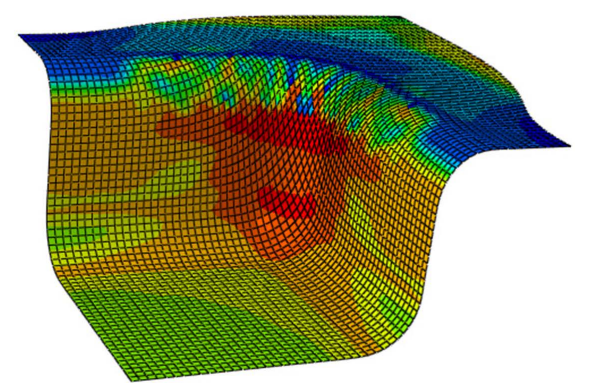

Figure 4. Distribution of maximum principal stress in the drawn cup.

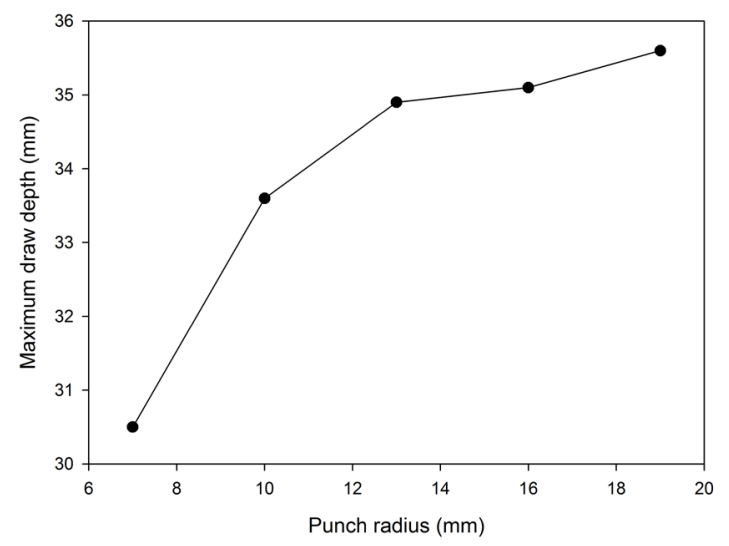

Figure 5. Effect of punch radius on maximum draw depth.

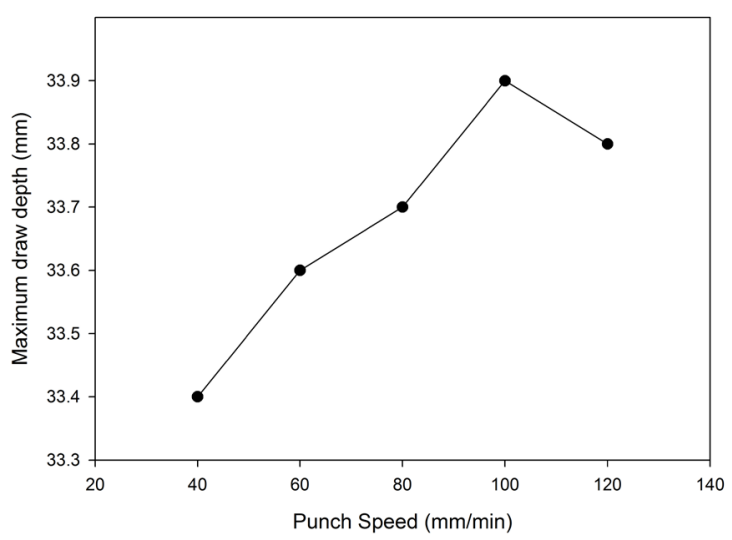

Figure 6. Effect of die corner radius on maximum draw depth. 


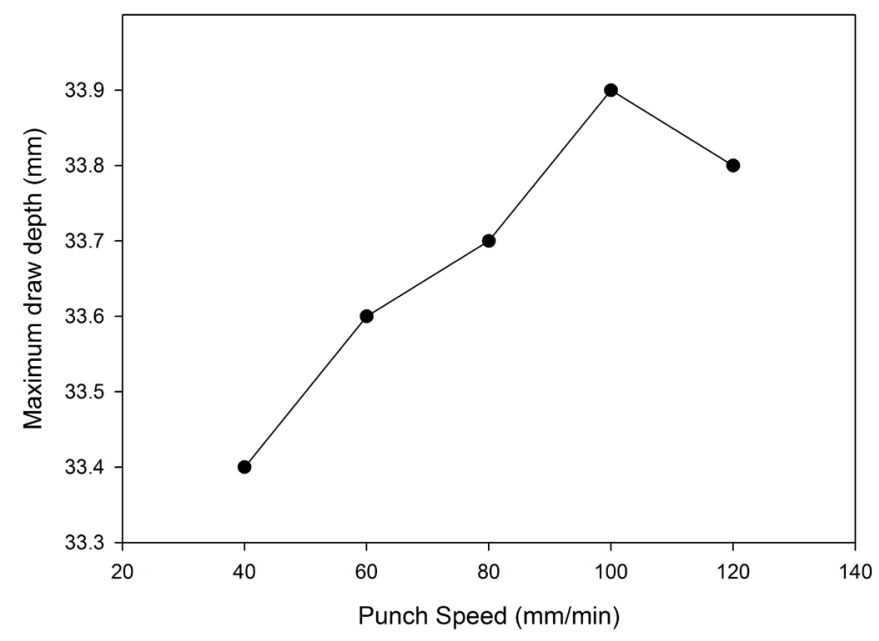

Figure 7. Effect of forming speed on maximum draw depth.

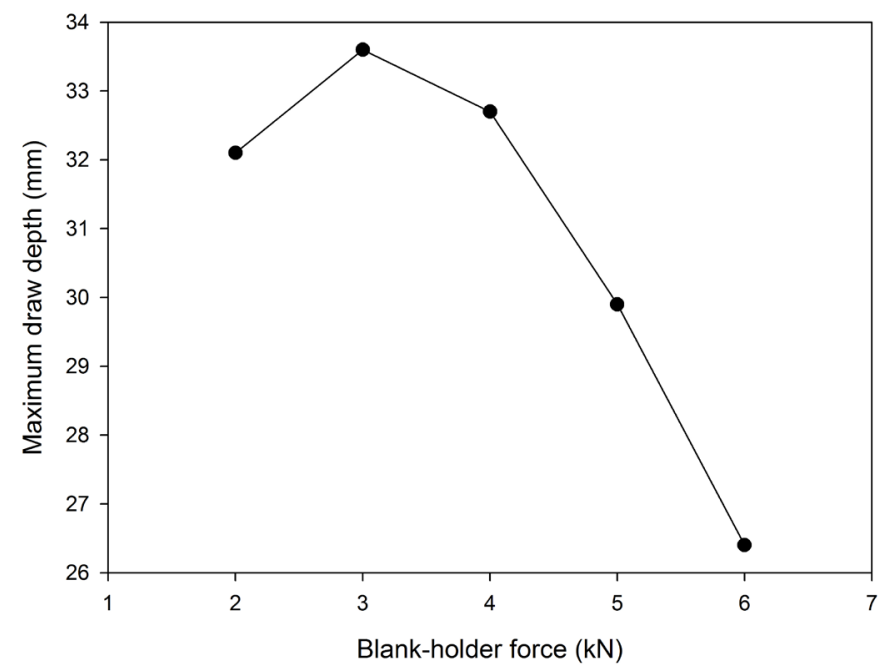

Figure 8. Effect of blank-holder force on maximum draw depth.

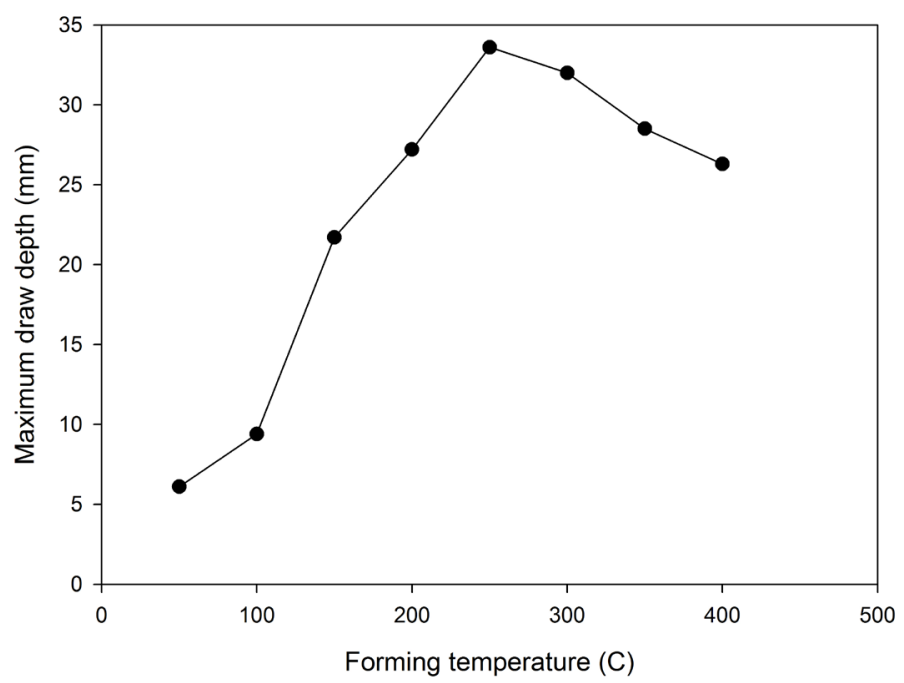

Figure 9. Effect of temperature on maximum draw depth. 


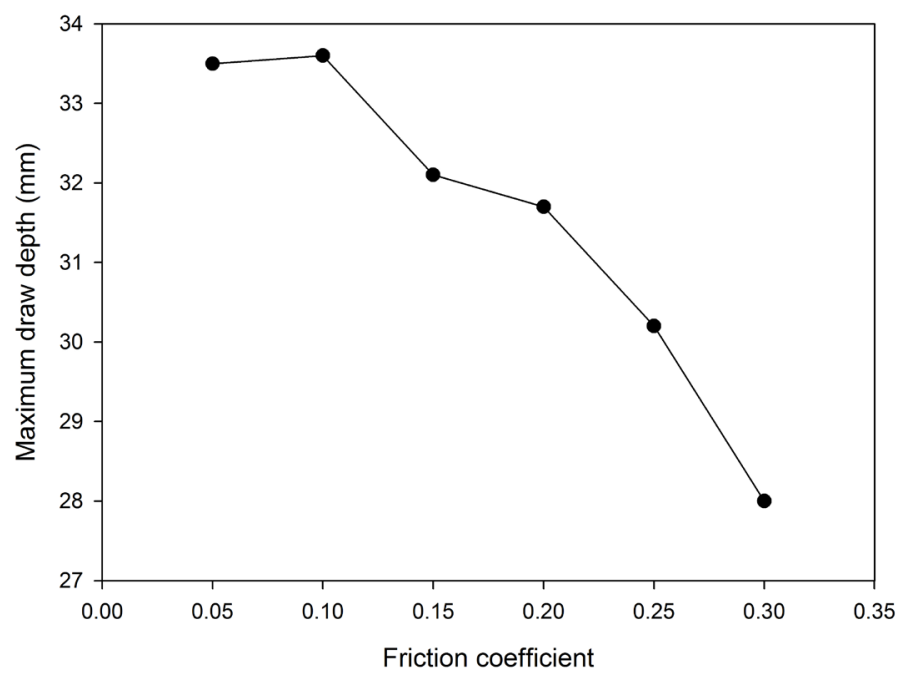

Figure 10. Effect of friction coefficient on maximum draw depth.

radius, die corner radius, punch speed, blank-holder force, friction coefficient and temperature. This will provide a design guideline for drawing of AZ61 square cups.

\section{References}

[1] Jiang, M.G., Yan, H. and Chen, R.S. (2015) Enhanced Mechanical Properties Due to Grain Refinement and Texture Modification in an AZ61 Mg Alloy Processed by Small Strain Impact Forging. Materials Science and Engineering A, 621, 204-211. http://dx.doi.org/10.1016/j.msea.2014.10.075

[2] Li, J.T., Xu, G.M., Yu, H.L., Deng, G.Y., Su, L.H., Lu, C., He, L.Z., Godbole, A. and Li, H.J. (2014) Optimization of Process Parameters in Twin-Roll Strip Casting of an AZ61 Alloy by Experiments and Simulations. International Journal of Advanced Manufacturing Technology, 76, 1769-1781. http://dx.doi.org/10.1007/s00170-014-6312-7

[3] Hlavácová, I., Palček, P., Chalupová, M. and Dresslerová, Z. (2013) Plastic Deformation Properties of Magnesium Alloy AZ61. Manufacturing Technology, 13, 313-319.

[4] Park, J.S. and Kim, J.M. (2013) Texture Development and Mechanical Behaviors of Extruded AZ61 Magnesium Alloys. Advanced Science Letters, 19, 705-709.

[5] Wu, H.-Y., Wu, C.-T., Yang, J.-C. and Lin, M.-J. (2014) Hot Workability Analysis of AZ61 Mg Alloys with Processing Maps. Materials Science and Engineering A, 607, 261-268. http://dx.doi.org/10.1016/j.msea.2014.04.017

[6] Liao, C., Wu, H., Wu, C., Zhu, F. and Lee, S. (2014) Hot Deformation Behavior and Flow Stress Modeling of Annealed AZ61 mg Alloys. Progress in Natural Science: Materials International, 24, 253-265. http://dx.doi.org/10.1016/j.pnsc.2014.04.006

[7] Olguín-González, M.L., Hernández-Silva, D., García-Bernal, M.A. and Sauce-Rangel, V.M. (2014) Hot Deformation Behavior of Hot-Rolled AZ31 and AZ61 Magnesium Alloys. Materials Science and Engineering A, 597, 82-88. http://dx.doi.org/10.1016/j.msea.2013.12.027

[8] Tsao, L.C., Huang, Y.-T. and Fan, K.-H. (2014) Flow Stress Behavior of AZ61 Magnesium Alloy during Hot Compression Deformation. Materials and Design, 53, 865-869. http://dx.doi.org/10.1016/j.matdes.2013.07.023

[9] Shin, K.-H., Lee, Y.-S. and Kim, H.S. (2014) The Flow Behavior Modeling of AZ61 Magnesium Alloy at Elevated Temperatures Considering the Effects of Strain Rate and Grain Size. International Journal of Precision Engineering and Manufacturing, 15, 745-751. http://dx.doi.org/10.1007/s12541-014-0395-9

[10] Liao, C.-H., Wu, H.-Y., Lee, S., Wu, C.-T. and Chiu, C.-H. (2013) Processing Map for Hot Deformation of Homogenized AZ61 Mg Alloy. Advanced Materials Research, 716, 240-243. http://dx.doi.org/10.4028/www.scientific.net/AMR.716.240

[11] Geranmayeh, A.R., Mahmudi, R., Movahedi-Rad, A. and Malekoshoaraei, M.H. (2012) High-Temperature Mechanical Properties of AZ61 and AZ61-0.7Si Magnesium Alloys. Kovove Materialy, 50, 393-397. 